\title{
Tracheal compression caused by an innominate artery aneurysm after thoracic aortic aneurysm repair in a patient with Marfan disease
}

\author{
P. W. de Feiter, MD, W. N. K. A. van Mook, MD, and M. J. H. M. Jacobs, MD, PhD, Maastricht, The Netherlands
}

$\mathrm{T}$ racheal compression caused by innominate artery anomalies is rare, and because of congenital anomalies, it is more recognized in children ${ }^{1-3}$ than in adults. ${ }^{4,5}$ Innominate artery aneurysms are even more uncommon than anomalies and are mainly described in relation to atherosclerosis $^{6}$ or Treponema pallidum infection. ${ }^{7}$ We report the case of a patient with Marfan disease and repeated sternotomy for aortic arch surgery in whom difficult weaning after repair of a thoracoabdominal aortic aneurysm led to the diagnosis of severe tracheal compression caused by an innominate artery aneurysm. Reoperation with exclusion of the aneurysm and transection of fibrotic tissue compromising the patency of the trachea improved tracheal stenosis and led to complete resolution of symptoms after successful extubation. To our knowledge, tracheal compression caused by an innominate artery aneurysm and fibrotic tissue after repeated sternotomy for aortic arch surgery in a patient with Marfan disease has not previously been reported.

\section{Clinical Summary}

A 43-year-old man was admitted to the intensive care unit because of weaning impairment. His medical history revealed hypertension, Marfan disease, Bentall procedure, partial aortic arch replacement, and replacement of the aortic arch with bypasses to the left common carotid, proximal innominate, and left subclavian arteries. Now a thoracoabdominal aortic aneurysm (Crawford extent II) with dissection necessitated aortic replacement from the previous graft to the iliac bifurcation. Extubation attempts early after surgical intervention failed. After transfer to the intensive care unit, weaning was impaired by desaturation caused by sputum retention. Resistance during advancement of a suction tube into the trachea was noted. Bronchoscopy showed $90 \%$ stenosis caused by external compression. A computed tomographic (CT) scan (Figure 1) visualized tracheal compression between the spinal column and the aneurysmatic innominate artery (maximal diameter of $3 \mathrm{~cm}$ ). During reoperation, the innominate artery aneurysm was excluded, new bypasses to the right carotid and subclavian arteries were constructed, and fibrotic tissue compromising the patency of the

\footnotetext{
From the Department of Surgery, University Hospital Maastricht, Maastricht, The Netherlands.

Received for publication July 27, 2004; accepted for publication Aug 5, 2004.

Address for reprints: P. W. de Feiter, MD, Department of Surgery, University Hospital Maastricht, P. Debyelaan 25, PO Box 9800, 6202 AZ Maastricht, The Netherlands (E-mail: pdf@home.nl).

J Thorac Cardiovasc Surg 2005;129:943-4

$0022-5223 / \$ 30.00$

Copyright $\odot 2005$ by The American Association for Thoracic Surgery

doi:10.1016/j.jtcvs.2004.08.017
}

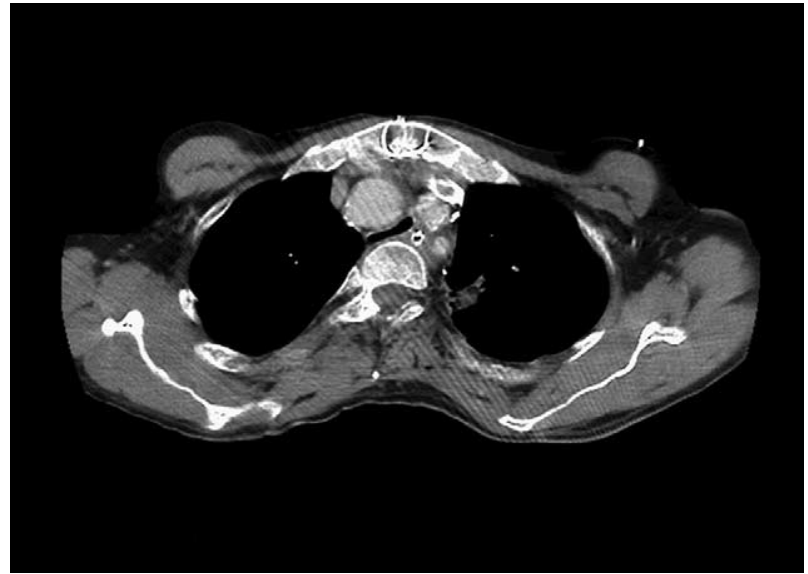

Figure 1. CT scan of the cervical region showing $90 \%$ tracheal stenosis caused by compression of the trachea between the spinal column and the aneurysmatic innominate artery $(\varnothing 3 \mathrm{~cm})$.

trachea was transected. During the operation (positive-pressure ventilation), bronchoscopy revealed spontaneous deployment and a fully patent lumen. Five days postoperatively, bronchoscopy during spontaneous breathing (zero positive pressure) revealed tracheomalacia and a remaining stenosis of $60 \%$. Several hours after extubation, coughing and increased inspiratory effort resulted in desaturation and stridor. Reintubation was necessary for another week. After 14 days, the patient was discharged from the hospital without stridor or dyspnea. A CT scan performed after 5 months showed persistent tracheomalacia with a diameter reduction of approximately $60 \%$ (Figure 2). The patient was free of symptoms.

\section{Discussion}

Innominate artery aneurysms are rare and described in relation to atherosclerosis $^{6}$ or syphilis ${ }^{7}$ and, to a lesser extent, to Takayasu disease, trauma, chronic dissection, bacterial infection, and collagen disorders. ${ }^{8}$ Three percent of the total number of cases of aneurysms correspond to aneurysms of the innominate artery. Tracheal compression caused by an innominate artery aneurysm has been reported before ${ }^{9-12}$ but never in a patient with Marfan disease after repeated sternotomy for aortic arch surgery. The development of an innominate artery aneurysm after a Bentall procedure has been reported once. ${ }^{13}$ In addition to clinical manifestations caused by tracheal compression, as in our patient, manifestations caused by compression of other structures have been reported, such as dysphagia; dysphonia; brachial plexus dysfunction with pain or with weakness of the upper extremity, or both; and superior vena cava syndrome with upper extremity edema. Other manifestations are due to embolism or thrombosis, causing (transient) cerebral ischemia, ocular deficits, or vertebro- 


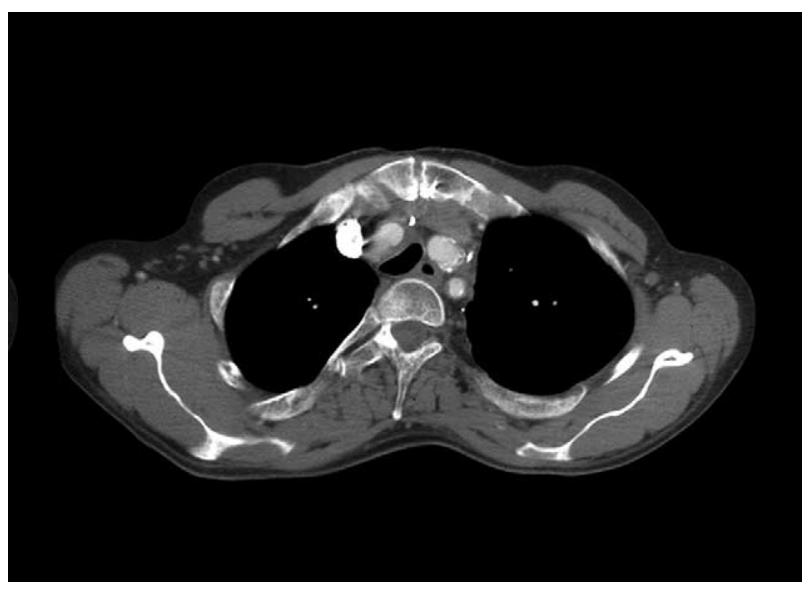

Figure 2. CT scan of the cervical region 5 months after exclusion of the innominate artery aneurysm and construction of new bypasses to the right carotid and subclavian artery. Persistent tracheomalacia with a diameter reduction of approximately $\mathbf{6 0} \%$ is visible.

basilar syndrome. A pulsatile mass might be present in the supraclavicular region, and the neck veins might be prominent. CT or angiography usually confirms the diagnosis. Surgical treatment is always necessary in symptomatic cases and must be seriously considered in asymptomatic and otherwise healthy patients. ${ }^{8}$ Surgical approach through a median sternotomy and bypass grafting from the ascending aorta to the subclavian and carotid arteries has good long-term patency. ${ }^{5}$ Surgical treatment can be especially difficult in patients with Marfan disease because of the usual habit of these patients, which is characterized by minimal dissection space in the neck and mediastinal region. In an elective setting, the mortality risk is $4 \%$ to $5 \%$ and increases up to $50 \%$ in case of emergency surgery for a ruptured aneurysm. ${ }^{8}$ Persistence of some degree of tracheomalacia is common but usually needs no further treatment. In case of recurrent episodes of dyspnea, stenting of the trachea can be considered.

\section{References}

1. Park CD, Waldhausen JA, Friedman S, Aberdeen E, Johnson J. Tracheal compression by the great arteries in the mediastinum. Report of 39 cases. Arch Surg. 1971;103:626-32.

2. Moes CA, Izukawa T, Trusler GA. Innominate artery compression of the trachea. Arch Otolaryngol. 1975;101:733-8.

3. Ardito JM, Ossoff RH, Tucker GF Jr, DeLeon SY. Innominate artery compression of the trachea in infants with reflex apnea. Ann Otol Rhinol Laryngol. 1980;89:401-5.

4. Rowe LD, Lowry LD, Keane WM, Fallenjad M. Aortic arch anomalies in adult disorders of deglutition. Ann Otol Rhinol Laryngol. 1978;87: 498-508.

5. Brewster DC, Moncure AC, Darling RC, Ambrosino JJ, Abbott WM. Innominate artery lesions: problems encountered and lessons learned. J Vasc Surg. 1985;2:99-112.

6. Schumacher PD, Wright CB. Management of of arteriosclerotic aneurysm of the innominate artery. Surgery. 1979;85:489-95.

7. Tadavarthy SM, Castaneda-Zuniga WR, Klugman J, Ben Shachar J, Amplatz K. Syphilitic aneurysms of the innominate artery. Radiology. 1981;139:31-4.

8. Kieffer E, Chiche L, Koskas F, Bahnini A. Aneurysms of the innominate artery: surgical treatment of 27 patients. J Vasc Surg. 2001;34: $222-8$.

9. Montgomery PQ, Stafford ND, Kerslake R. Tracheal compression by an innominate artery aneurysm. Eur J Vasc Surg. 1987;1:425-7.

10. Sader AA, Cherri J, Ceneviva R. Massive tracheal necrosis due to compression by an innominate artery aneurysm associated with a grade IV Chagasic megaesophagus and chronic duodenal ulcer. Chest. 1999; $116: 837-40$.

11. Munro NC, Soppitt D, Brewis RA. Tracheal stenosis due to bilateral arterial aneurysms. Thorax. 1994;49:183-4.

12. Tominaga R, Tanaka J, Kawachi Y, et al. Surgical treatment of respiratory insufficiency due to tracheobronchial compression by aneurysms of the ascending aorta and innominate artery. $J$ Cardiovasc Surg (Torino). 1988;29:413-7.

13. Sakakibara N, Fujiwara H, Maemura T, Goto K, Funazu H, Konno S. [Resection of aneurysm of the brachiocephalic trunk and left to right carotid arterial bypass for severe tracheal stenosis after Bentall's operation]. Nippon Kyobu Geka Gakkai Zasshi. 1985; 33:98-103. 